\title{
FITOREMEDIASI TANAH TERCEMAR PELUMAS BEKAS MENGGUNAKAN AKAR WANGI (VETIVERIA ZIZANIOIDES)
}

\author{
Alif Yoga Winata*1) ${ }^{*}$ dan Bieby Voijant Tangahu ${ }^{1)}$ \\ ${ }^{1)}$ Departemen Teknik Lingkungan,Institut Teknologi Sepuluh Nopember (ITS), \\ Kompleks Kampus ITS, Sukolilo, Surabaya, 60111 \\ ${ }^{*}$ E-mail: alifyoga96@gmail.com
}

\begin{abstract}
Abstrak
Polusi lingkungan yang disebabkan oleh aktivitas industri dan kendaraan telah meningkat pesat. Banyak bengkel-bengkel yang tidak tahu bagaimana cara mengelola sampah mereka. Untuk menyingkirkan masalah mereka, pelumas yang sudah terpakai langsung dibuang di tanah atau daerah perairan. Pengelolaan limbah berbahaya yang buruk dari pelumas yang dihasilkan berdampak pada tercecernya pelumas bekas yang tersebar di tanah dalam jumlah besar. Pelumas bekas mengandung kompleks campuran hidrokarbon yang mempengaruhi tanaman secara merugikan dengan menciptakan kondisi yang membuat nutrisi penting seperti nitrogen dan oksigen yang dibutuhkan untuk pertumbuhan tanaman tidak tersedia bagi mereka dan menyebabkan masalah parah pada ekosistem tanah dan rhizosfer. Efek zat beracun pada organisme, populasi dan komunitas berkisar dari sedang sampai mematikan. Fitoremediasi tanah yang terkontaminasi menawarkan pendekatan ramah lingkungan dan hemat biaya untuk membersihkan polutan beracun di lingkungan.
\end{abstract}

Tidak seperti teknologi remediasi lainnya, fitoremediasi tidak invasif dan pada prinsipnya mempertahankan proses biologis tanah tetap aktif. Metode ini menggunakan tanaman untuk detoksifikasi, pemulihan dan pemurnian media lingkungan. Kisaran aplikasi fitoremediasi cukup luas mulai dari logam berat hingga polutan organik seperti hidrokarbon minyak bumi. Analisis statistik menunjukkan bahwa penambahan pupuk memiliki efek positif dan terukur pada kadar klorofil. Pupuk spesifik dapat merangsang pengalihan unsur tertentu, termasuk logam berat, agar lebih tersedia bagi bentuk tanaman dan meningkatkan akumulasi logam di tanaman.

Akar wangi dapat bertahan pada rentang suhu antara -14 dan $55^{\circ} \mathrm{C}$ dan bertahan dalam kondisi ekstrim. Akar wangi dapat tumbuh di berbagai tingkat nutrisi dan faktor abiotik yang tidak mencukupi. Telah ditunjukkan bahwa kadar air merupakan faktor yang sangat penting dalam hal pertumbuhan. Dengan tekanan kadar air yang berbeda, hal itu dapat menghasilkan hasil degradasi yang berbeda. Penelitian menunjukkan bahwa kemampuan degradasi pelumas bekas pada konsentrasi $4 \%$ oleh akar wangi pada tiap variabel A1 $=19,65 \%$, $\mathrm{A} 2=17,78 \%, \mathrm{~A} 3=16,45 \%, \mathrm{~B} 1=21,68 \%, \mathrm{~B} 2=19,37 \%, \mathrm{~B} 3=20,04 \%$ dengan kondisi optimal pada penambahan pupuk sebesar 80 gram dan frekuensi penyiraman 1 kali sehari.

Kata kunci: Akar wangi, Fitodegradasi, Fitoremediasi, Kelembaban, Pelumas bekas, Pemupukan. 


\begin{abstract}
Environmental pollution caused by industrial activities and motor vehicles has increased rapidly. Many automobile repair shops are oblivious on how to manage their waste. To solve their problems, used lubricant would directly be disposed of to the ground or water bodies. The poor hazardous waste management of lubricant generated cause a large amount of scattered used lubricant on the ground. Used lubricant contains complex hydrocarbon mixtures that affect plants detrimentally by creating a condition where essential nutritions such as nitrogen and oxygen needed for plant growth would not be available for them and thus creates a severe problem in the rhizosphere and soil ecosystem. The effects of toxic substances on organisms, the population and communities range from moderate to lethal. Phytoremediation of contaminated soil offers an environmentally friendly and cost-effective approach to clean the environment from toxic pollutants.
\end{abstract}

Unlike any other remediation technologies, phytoremediation is not invasive and in principal allows the biological processes of the soil to remain active. This method uses plants for the detoxification, remediation and purification of environmental media. Phytoremediation covers a wide range of application, from heavy metals to organic pollutants such as petroleum hydrocarbons. Statistical analysis showed that the addition of fertilizers yields measurable positive effects on the level of chlorophyll. Specific fertilizers can stimulate the transfer of certain substances, including heavy metals, so that they are in available forms for plants and increase metal accumulation in the plants.

Vetiver can withstand temperatures ranging from -14 to $55^{\circ} \mathrm{C}$ and survive in extreme conditions. Vetiver can grow in various levels of inadequate nutrition and poor abiotic factors. It has been shown that water level was an essential factor in growth. Under different levels of water pressure, different degradation results would occur. Research showed that the degradation of used lubricant by vetiver at $4 \%$ of concentration for each variable are as follows: $A 1=19.65 \%, A 2=17.78 \%, A 3=16.45 \%, B 1=21.68 \%, B 2=19.37 \%, B 3=$ $20.04 \%$. Optimum conditions were obtained by adding 80 grams of fertilizer and watering period of once a day.

Keywords: Vetiver, Phytodegradation, Phytoremediation, Humidity, Used lubricant, Fertilization. 


\section{PENDAHULUAN}

Semakin berkembangnya industri dan pesatnya pertambahan jumlah kendaraan dewasa ini menyebabkan kebutuhan perawatan mesin produksi maupun kendaraan semakin meningkat. Limbah pelumas bekas yang sudah tidak terpakai biasanya tidak dikelola sesuai dengan prosedur, khususnya pada usaha perbengkelan yang tidak memiliki sistem pengelolaan limbah yang baik. Minyak pelumas bekas mengandung campuran kompleks hidrokarbon parafin, naftalena, hidrokarbon aromatik dan berbagai kontaminan yang mengandung satu atau lebih komponen (Ayoola $d k k .$, 2012). Tumpahan minyak mengandung minyak mentah atau produk minyak sulingan seperti minyak bahan bakar dan minyak pelumas. Senyawa beracun dalam minyak mentah terdiri dari berbagai hidrokarbon, senyawa nitrogen-oksigen, senyawa sulfur, dan logam berat, yang dapat menyebabkan efek akut dan kronis pada flora dan fauna (Murakami $d k k$., 2011). Tanaman di area akuatik dan terestrial dapat terkena kerusakan kimia dan fisik oleh hidrokarbon minyak. Daun tanaman yang tercemar dapat mengurangi fotosintesis dan pengaturan suhu, sementara pelapisan akar dapat mengganggu struktur akar hingga serapan air dan hara (Kuo dkk., 2014). Morfologi yang membedakan akar wangi adalah sistem akar yang besar dan terstruktur dengan baik. Dalam kondisi optimal, spesies dapat tumbuh dengan sangat cepat, mencapai kedalaman akar hingga $4 \mathrm{~m}$ pada tahun pertama. Menunjukkan kekuatan penetrasi yang luar biasa, akar akar wangi mampu melewati tanah yang sulit, termasuk tanah aspal. Karena tanaman tidak memiliki stolon atau rimpang, akar wangi mudah dikendalikan. Biasanya, sistem akar tumbuh lurus ke bawah tanpa bersaing dengan vegetasi disekitarnya. Oleh karena itu, tanaman ini dapat memenuhi kebutuhannya sendiri (Greenfield, 2000). mengatakan bahwa tumbuhan memiliki mekanisme yang efisien untuk memperoleh nutrisi dari lingkungan pada kondisi rendah nutrient, kemudian dipindahkan dan disimpan dalam organ tertentu. Mekanisme tersebut juga dilakukan dalam penyerapan zat racun yang memiliki kandungan kimia serupa dengan zat esensial yang dibutuhkan tumbuhan. Proses absorpsi racun termasuk logam berat dapat terjadi melalui beberapa bagian tumbuhan dengan mekanisme translokasi (Soemirat, 2003). Eksudat ini dapat memulai respon chemotactic mikroba untuk motilitas menuju akar dan pembentukan kolonisasi akar, yang akibatnya merangsang pertumbuhan dan aktivitas mikroorganisme untuk degradasi polutan organik (Gerhardt $d k k ., 2009)$.

\section{METODA}

\section{Ide Penelitian}

Ide penelitian ini berasal dari banyaknya tumpahan minya di berbagai area yang diakibatkan oleh perbengkelan atau pembuangan pelumas bekas secara illegal dan menyebabkan menurunnya kualitas tanah. Dari permasalahan tersebut, diperlukan penelitian mengenai upaya penurunan konsentrasi pelumas bekas pada media tanah menggunakan akar wangi. Dengan demikian dapat dilakukan upaya untuk mereduksi pelumas bekas hasil pencemaran tersebut.

\section{Studi Literatur}

Studi literatur dilakukan dengan tujuan untuk mendapatkan dasar teori yang kuat yang berkaitan dengan penelitian ini, sehingga dapat dijadikan acuan dalam melaksanakan kegiatan penelitian. Studi literatur dilakukan dengan mencari bahan-bahan yang menunjang penelitian dari sumber-sumber yang ada. Sumber literatur meliputi text book, modul, jurnal/artikel ilmiah, laporan penelitian, tugas akhir, dan tesis terdahulu yang berhubungan dengan penelitian.

\section{Pengumpulan Data}


Data primer yang dibutuhkan dalam penelitian ini diperoleh dari hasil pengamatan dan pengukuran di lokasi studi serta hasil analisis laboratorium. Pengukuran di lokasi studi meliputi pengukuran fisik tanaman dan media. Penelitian laboratorium meliputi analisis minyak dan lemak dan analisis mikroorganisme.

\section{Pelaksanaan Penelitian}

Pelaksanaan penelitian ini dilakukan dengan persiapan propagasi. Indukan diletakkan pada bak propagasi dengan media tanah dan pupuk sebesar 63,5 gram. Pengambilan sampel anakan kemudian akan digunakan untuk fase aklimatisasi, Range Finding Test dan penelitian utama. Pengukuran panjang daun dan panjang akar dilakukan di lokasi studi. Pengambilan sampel media untuk analisis minyak dan lemak dan mikroorganisme dilakukan dengan metode komposit sampling. Variasi yang diberikan berupa penyiraman yaitu 1 kali sehari, 3 hari sekali dan 5 kali sekali, juga konsentrasi pupuk 40 gram/reaktor dan 80 gram/reaktor.

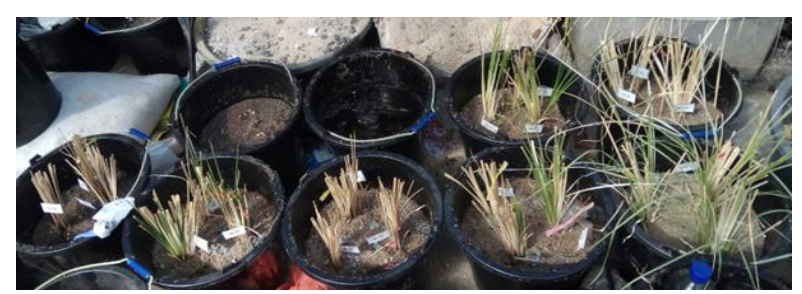

Gambar 1. Reaktor dan Tanaman Penelitian Utama

\section{Pengolahan Data}

Dilakukan pengolahan data dari hasil penelitian lapangan dan laboratorium. Pengolahan data meliputi perhitungan laju tanaman, perpanjangan akar, fraksi kering, suhu dan kelembapan, peran mikroorganisme dan kandungan minyak dan lemak.

\section{HASIL DAN PEMBAHASAN}

\section{Penelitian Pendahuluan}

\section{Propagasi}

Akar wangi membutuhkan waktu 10-14 hari untuk membentuk tunas baru dari rumpun indukan secara meluas. Tunas menempel pada indukan kemudian membentuk perakaran muda yang berwarna putih, rentan dan berdiameter lebih besar daripada akar induk utama yang bersifat lebih lentur, berwarna coklat kehitaman dan berdiameter lebih kecil namun kuat. Laju pertumbuhan tunas pada tahap propagasi sebesar 2-2,5 $\mathrm{cm}$. Laju pertumbuhan yang tinggi didukung oleh jangkauan sistem perakaran yang luas, kebutuhan nutrien yang optimal dari tanah, dan rumpun indukan yang kuat dengan distribusi nutrien yang menyeluruh ke seluruh batang.

\section{Aklimatisasi dan Range Finding Test}

Aklimatisasi juga berfungsi untuk memberi waktu bakteri rhizobakteria dalam membentuk koloni yang akan membantu dalam degradasi pelumas bekas. Bakteri seperti ini umumnya disebut sebagai Plant Growth-Promoting Rhizobacteria (Lugtenberg dan Faina, 2009).

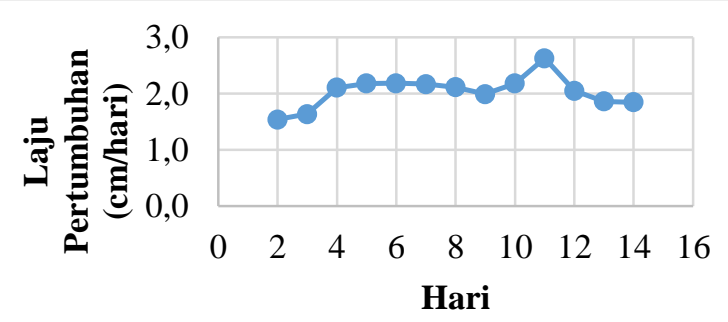

Gambar 2. Laju Pertumbuhan pada Masa Aklimatisasi

Laju pertumbuhan rata-rata pada daun pada masa aklimatisasi berturut-turut $\mathrm{C} 0(0 \%)=$ $1,952 \mathrm{~cm} /$ hari, $\mathrm{C} 1(3 \%)=1,667 \mathrm{~cm} /$ hari, $\mathrm{C} 2$ $(4 \%)=1,738 \mathrm{~cm} /$ hari, C3 $(5 \%)=2,474$ $\mathrm{cm} /$ hari, C4 $(6 \%)=1,443 \mathrm{~cm} /$ hari, dan C5 $(7 \%)=2,069 \mathrm{~cm} /$ hari. 
Pada Range Finding Test didapatkan hasil pengukuran suhu sebagai berikut :

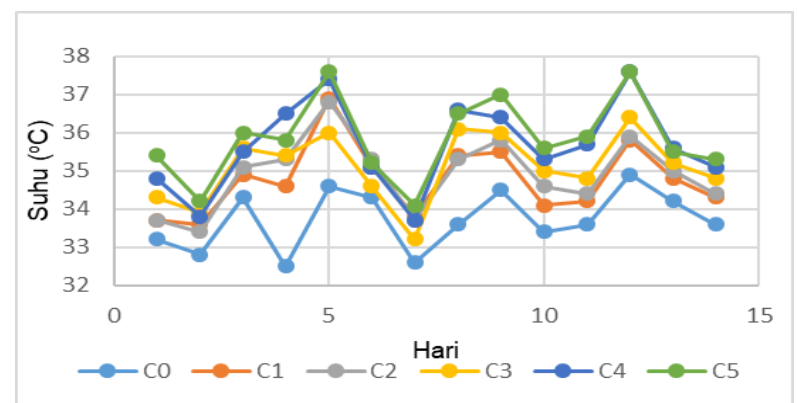

Gambar 3. Suhu Reaktor saat RFT

Mikroorganisme mesofilik dapat bekerja karena suhu optimum untuk melakukan metabolisme berkisar $25^{\circ} \mathrm{C}-40^{\circ} \mathrm{C}$ (Ardhanie, 2008). RFT dilakukan selama 14 hari dan didapatkan laju pertumbuhan sebagai berikut :

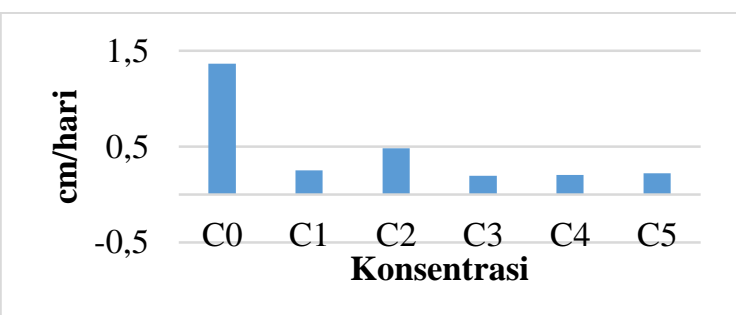

Gambar 3. Suhu Reaktor saat RFT

Rata-rata pertumbuhan dari ketiga tanaman pada tiap konsentrasi berturut-turut adalah $\mathrm{C} 0$ $=1,362 \mathrm{~cm} /$ hari, $\mathrm{C} 1=0,252 \mathrm{~cm} /$ hari, $\mathrm{C} 3=$ $0,194 \mathrm{~cm} /$ hari, $\mathrm{C} 4=0,205 \mathrm{~cm} /$ hari, $\mathrm{C} 5=$ $0,220 \mathrm{~cm} /$ hari. Hasil rasio pertambahan panjang akar pada 3\%, 4\%, 5\%, 6\% dan 7\% masing-masing sebesar 0,$473 ; 0,333 ; 0,377$; 0,380; 0,268; dan 0,237. nutrien. Fraksi kering diukur dengan menentukan berat basah dan berat kering terlebih dahulu.

Tabel 1. Fraksi Kering saat RFT

\begin{tabular}{lcccccc}
\hline Keterangan & $\mathrm{C} 0$ & $\mathrm{C} 1$ & $\mathrm{C} 2$ & $\mathrm{C} 3$ & $\mathrm{C} 4$ & $\mathrm{C5}$ \\
\hline Daun & 0,353 & 0,435 & 0,418 & 0,457 & 0,466 & 0,468 \\
Akar & 0,190 & 0,191 & 0,258 & 0,444 & 0,437 & 0,433 \\
\hline
\end{tabular}

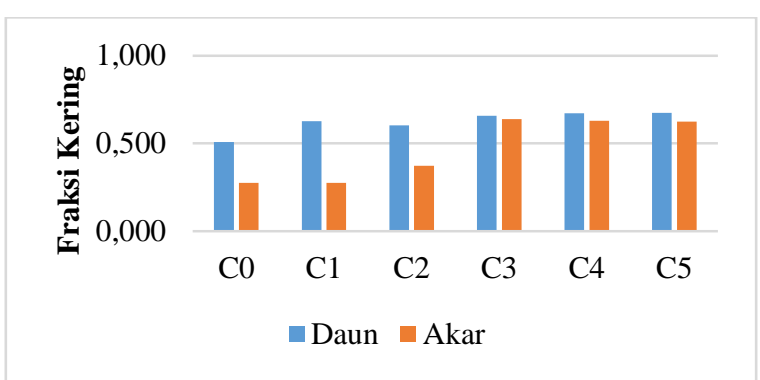

Gambar 3. Grafik Fraksi Keing saat RFT

Berdasarkan tabel dapat dilihat bahwa pada sampel tanaman C0, C1, C2 memiliki fraksi kering akar dibawah 0,5 yang mengindikasikan kemampuan penyerapan air oleh akar masih berjalan optimal. Pada konsentrasi C3, C4, C5 fraksi kering di atas 0,6 . Tingginya konsentrasi pelumas bekas yang membentuk film pada permukaan air maupun akar menyulitkan akar untuk melakukan penyerapan air. Berdasarkan RFT, maka ditentukan konsentrasi untuk penelitian utama adalah $4 \%$.

\section{Penelitian Utama}

1. Laju Pertumbuhan

Laju pertumbuhan didapatkan dari selisih panjang tanaman dibagi hari tumbuh tanaman pada media tanam selama penelitian utama berlangsung, sehingga dapat dihitung melalui persamaan berikut :

$$
\mathrm{V}=\frac{(L 2-L 1)}{T}
$$

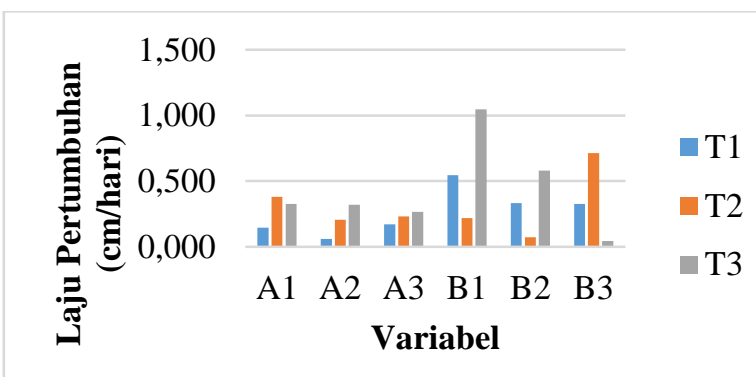

Gambar 4. Laju Pertumbuhan pada Uji Utama

Pada Gambar 4 dapat dilihat bahwa pada variabel A (konsentrasi pupuk 40 gram/reaktor) dengan tiga variabel 
penyiraman yang berbeda memiliki rata-rata pertumbuhan lebih rendah dibandingkan dengan variabel B (konsentrasi pupuk 80 gram per/reaktor), sehingga dapat diduga bahwa peran pupuk pada awal masa penelitian memiliki fungsi penting dalam pembentukan komunitas mikroorganisme dalam akar dalam pemecahan pencemar pelumas bekas. Pada variabel 1,2 dan 3 dapat dilihat bahwa frekuensi penyiraman sekali sehari memiliki nilai laju pertumbuhan yang lebih tinggi daripada frekuensi penyiraman 3 hari sekali maupun 5 hari sekali, sehingga dapat diduga bahwa penyiraman sehari sekali menjaga kelembaban tanah tetap terjaga dan berada pada rentang yang optimal untuk pertumbuhan mikroorganisme, baik rhizobakteria maupun mikoriza.

\section{Fraksi Kering}

Analisis fraksi kering dapat dihitung setelah mendapatkan data berat basah dan berat kering pada akhir penelitian. Fraksi kering adalah rasio yang digunakan untuk mengukur jumlah fase cair (atau fase uap) pada bagian tumbuhan.

Tabel 2. Fraksi Kering saat Uji Utama

\begin{tabular}{lcccccc}
\hline Keterangan & $\mathrm{A} 1$ & $\mathrm{~A} 2$ & $\mathrm{~A} 3$ & $\mathrm{~B} 1$ & $\mathrm{~B} 2$ & $\mathrm{~B} 3$ \\
\hline Daun & 0,381 & 0,447 & 0,410 & 0,384 & 0,397 & 0,407 \\
Akar & 0,344 & 0,392 & 0,353 & 0,322 & 0,341 & 0,348 \\
\hline
\end{tabular}

Variabel 1 (penyiraman satu hari sekali) menujukkan nilai fraksi kering yang relatif kecil dibandingkan variabel 2 (penyiraman tiga hari sekali) dan variabel 3 (penyiraman lima hari sekali). Pada variabel 2 dan 3 beberapa bagian tanaman mengalami layu dan kering pada hari ke-30, sehingga fraksi kering dari daun bernilai lebih besar. Nilai fraksi kering akar berbanding lurus dengan fraksi kering daun, yang mengindikasikan bahwa proses transfer dari media tanam ke akar dan akar ke daun tidak berjalan optimal.
3. Suhu dan Kelembapan

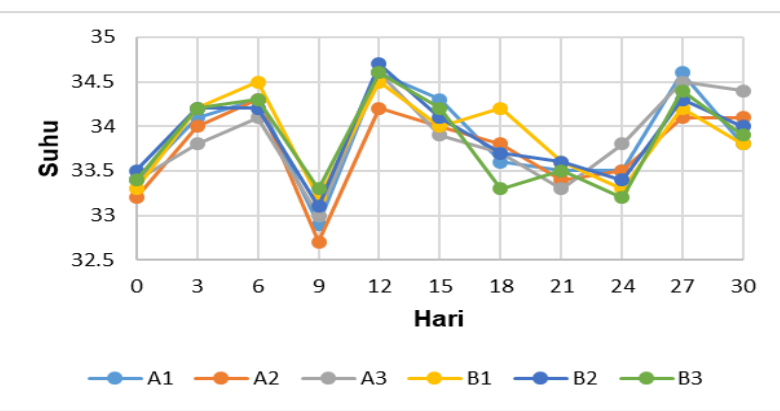

Gambar 5. Pengukuran Suhu pada Uji Utama

Pada hari ke-3 hingga hari ke-15 variabel B memiliki suhu lebih tinggi. Hal ini menandakan bahwa adanya aktivitas mikroorganisme pada media tanah yang bekerja lebih dominan karena pasokan pupuk yang lebih banyak daripada variabel A. Sedangkan pada hari ke-24 hingga hari ke-30 variabel A memiliki suhu yang lebih tinggi. Adanya penurunan konsentrasi pelumas bekas pada hari sebelumnya akibat dari aktivitas akar wangi dan mikroorganisme yang terbentuk lebih cepat sehingga saat memasuki hari ke-24 komunitas mikroorganisme rhizosfer variabel A sudah memasuki fase stationer, sedangkan variabel B baru memasuki fase eksponensial.

Grafik untuk tiap variabel memiliki kecenderungannya masing masing. Hal ini disebabkan karena penambahan air pada variabel 1 setiap harinya bernilai konstan. Sedangkan pada variabel 2 dan 3 penambahan

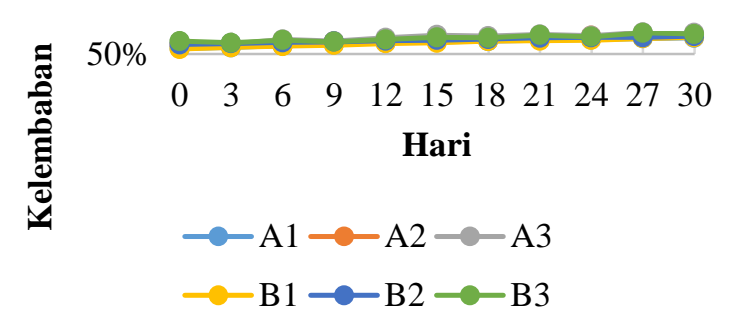

Gambar 6. Pengukuran Kelembapan pada Uji Utama

air dengan jumlah yang melebihi kebutuhan tanaman dan mikroorganisme pada hari 
dimana penyiraman dilakukan akan berimbas pada aktivitas tanaman maupun komunitas rhizosfer. Sebagai contoh pada variabel 2 pada hari pertama dilakukan penyiraman sebanyak $300 \mathrm{ml}$, pada hari ke-2 dan ke-3 kadar air pada media lebih rendah daripada hari pertama, kemudian pada hari ke-4 dilakukan penyiraman kembali. Hal ini menyebabkan fluktuasi kadar air pada media sehingga proses metabolisme akar wangi dan mikroorganisme mengalami perubahan.

\section{Analisis Minyak dan Lemak}

Analisis terhadap konsentrasi pelumas bekas merupakan analisis utama untuk menentukan nilai persen removal yang dapat disisihkan oleh tanaman dari media. Pengambilan sampel secara komposit, sehingga didapatkan pelumas bekas secara merata dari permukaan media hingga lapisan terdalam media, sehingga polutan yang biasanya mengendap di dasar reaktor dapat terambil.

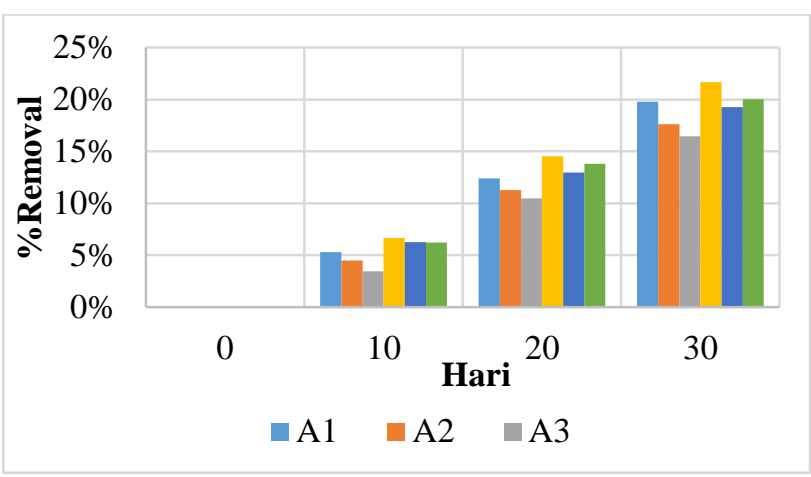

Grafik di atas memperlihatkan peningkatan degradasi pelumas bekas dari waktu ke waktu. Pada variabel B1, B2, B3 memiliki \% removal yang lebih tinggi. Hal ini terjadi karena konsentrasi pupuk sebagai suplai nutrisi untuk mikroorganisme tersedia secara melimpah, sehingga aktivitas mikroorganisme berjalan secara optimal. Hasil pengamatan yang telah dilakukan memperlihatkan bahwa tinggi konsentrasi pupuk yang diberikan memiliki berbanding lurus dengan penurunan konsentrasi pelumas bekas. Nilai removal pelumas bekas berturut-turut pada variabel $\mathrm{A} 1=19,65 \%, \quad \mathrm{~A} 2=17,78 \%, \quad \mathrm{~A} 3=16,45 \%$, $\mathrm{B} 1=21,68 \%, \mathrm{~B} 2=19,37 \%, \mathrm{~B} 3=20,04 \%$.

\section{Peran Mikroorganisme}

Aktivitas mikroorganisme memasuki fase eksponensial, sehingga mempercepat proses degradasi pelumas bekas komunitas rhizosfer yang sudah tebentuk secara kompleks dengan moikroorganisme yang heterogen memiliki fungsinya masing-masing seperti pemecahan rantai karbon, pembentukan asam organik dan konversi molekul menjadi organik menjadi senyawa inorganik yang dapat diserap oleh tanaman.

\begin{tabular}{|l|l|}
\hline Variabel & Jumlah Bakteri \\
\hline A1 & $20 \times 10^{8}$ koloni \\
\hline A2 & $11 \times 10^{8}$ koloni \\
\hline A3 & $17 \times 10^{8}$ koloni \\
\hline B1 & $54 \times 10^{8}$ koloni \\
\hline B2 & $19 \times 10^{8}$ koloni \\
\hline B3 & $31 \times 10^{8}$ koloni \\
\hline
\end{tabular}

Tanah rhizosfer yang mengelilingi akar tanaman kaya akan mikroorganisme memiliki interaksi konstan antara tumbuhan dan mikroba di rhizosfer yang dimediasi oleh bahan kimia yang ada dalam eksudat akar. Interaksi dapat memiliki efek positif atau negatif pada tanaman atau mikroba (Prithiviraj $d k k .$, 2005). Senyawa kimia yang ada dalam eksudat akar memainkan peran penting dalam pembentukkan asosiasi simbiosis antara jamur mikoriza dan tanaman. Lebih dari $80 \%$ dari semua tanaman darat membentuk asosiasi simbiosis dengan mikoriza, yang meningkatkan serapan fosfor dan memberi toleransi terhadap biotik dan abiotik pada tanaman. Pencabangan jamur hyphal merupakan perintis penting dari kolonisasi akar dan dimediasi oleh faktor percabangan (Branching Factors) yang ada di eksudat tanaman inang (Bluee $d k k$., 200).

Berdasarkan data yang didapatkan pengukuran parameter lainnya, aktivitas mikroorganisme dipengaruhi oleh perlakuan yang diterapkan pada setiap variabel. Jumlah koloni pada variabel B (konsentrasi pupuk 80 gram) cenderung memiliki jumlah koloni yang lebih banyak daripada variabel A 
(konsentrasi pupuk 40 gram). Metabolisme dan aktivitas mikroorganisme dipengaruhi oleh besarnya konsentrasi pupuk yang berbanding lurus dengan fase pertumbuhan mikroorganisme, sedangkan parameter kelembapan berbanding terbalik dengan aktivitas bakteri. Akar wangi akan mengalami tekanan turgor, sedangkan sel bakteri mengalami kondisi hipotonik dikarenakan banyaknya konsentrasi air yang masuk ke dalam sel akibat difusi. Oleh karena itu, jumlah koloni bakteri pada variabel 1 (frekuensi penyiraman 1 kali sehari) lebih banyak daripada Variabel 2 dan 3. Kondisi lingkungan yang tidak banyak berubah membuat mikroorganisme tidak banyak beradaptasi pada tiap periode penyiraman sehingga fase pertumbuhan bakteri berjalan optimal.

\section{KESIMPULAN}

1. Konsentrasi optimal untuk degradasi pelumas bekas berdasarkan kondisi fisik tanaman sebesar $4 \%$ dari berat total media.

2. Efisiensi removal pelumas bekas oleh akar wangi pada akhir penelitian berturut-turut pada variabel konsentrasi pupuk 40 gram dan penyiraman 1 hari sekali sebesar $19,65 \%$, konsentrasi pupuk 40 gram dan penyiraman 3 hari sekali sebesar $17,78 \%$, konsentrasi pupuk 40 gram dan penyiraman 5 hari sekali sebesar 16,45\%, konsentrasi pupuk 80 gram dan penyiraman 1 hari sekali sebesar 21,68\%, konsentrasi pupuk 80 gram dan penyiraman 3 hari sekali sebesar 19,37\%, konsentrasi pupuk 80 gram dan penyiraman 5 hari sekali sebesar 20,04\%.

3. Kondisi optimum adalah variabel B1, yaitu konsentrasi penambahan pupuk sebesar 80 gram dan frekuensi penyiraman sehari sekali dengan persen removal sebesar $21,68 \%$.

\section{Ucapan terima kasih}

Penulis mengucapkan terimakasih kepada Ibu Bieby Voijant Tangahu, ST, MT, PhD selaku pembimbing, serta kepada dosen penguji tugas akhir yang telah memberi kritik dan saran terhadap penulisan jurnal ini.

\section{DAFTAR PUSTAKA}

Ardhanie, P.R. (2003). Biodegradasi Oli Bekas Pada Media Tanah. Tugas Akhir Jurusan Teknik Lingkungan, FTSP, ITS Surabaya.

Ayoola, S. O., Akaeze, C. O. (2012). Genotoxic Evaluation Toxicity of Spent Engine Oil On Clarias gariepinus. Research Journal of Environmental Toxicology 6: 133-141.

Buee, M., Rossignol, M., Jauneau, A., Ranjeva, R., Be'card, G. (2000). The pre-symbiotic growth of arbuscular mycorrhizal fungi is induced by a branching factor partially purified from plant root exudates. Mol. Plant Microbe Interact. 2000, 13, 693-698.

Gerhardt, K.E., Huang, X.D., Glick, B.R. \& Greenberg, B.M. (2009). Phytoremediation and Rhizoremediation of Organic Soil Contaminants: Potential and Challenges. Plant Science, Vol.176, No.1, pp.20-30, ISSN 0168-9452

Greenfield, J.C. (2000). Vetiver grass: An Essential Grass for the Conservation of Planet Earth. The Vetiver Network International.

Kuo, H.C., D.F. Juang, L. Yang, W.C. Kuo, Y.M. Wu. (2014). Phytoremediation of Soil Contaminated by Heavy Oil with Plants Colonized by Mycorrhizal Fungi. International Journal Environmental Science Technoogy (2014) 11:1661-1668. 
Lugtenberg, B., Faina K. (2009). PlantGrowth-Promoting Rhizobacteria. Annual Review of Microbiology 2009 63:541-556.

Morris, L., Colombo V., Hassell, K., Kellar, C., Leahy, P., Long, Sara M., Myers, J.H., Pettigrove, V. (2016). "Municipal Wastewater Effluent Licensing : A Global Perspective and Recommendations for Best Practice". Science of The Total Environment: 13.

Murakami CJ, et al. (2011). Composition and Acidification of the Culture Medium Influences Chronological Aging Similarly in Vineyard and Laboratory Yeast. PLoS One 6(9):e24530

Prithiviraj, B., Bais, H. P., Weir, T., Suresh, B., Najarro, E. H., Dayakar, B. V., Schweizer, H. P. \& Vivanco, J. M. (2005). Down regulation of virulence factors of Pseudomonas aeruginosa by salicylic acid attenuates its virulence on Arabidopsis thaliana and Caenorhabditis elegans. Infect Immun 73, 5319-5328.

Soemirat J. (2003). Toksikologi Lingkungan. Yogyakarta (ID): Gajah Mada University Press. 